When a man puts his hand to the plow and the plow strikes a stump, sometimes it is better to turn back. From that time on 1 believed in large doses. Thereafter when a patient brought me a quart bottle for medicine and I wanted to give him eight doses, I put in the proper quantity of medicine, then filled the bottle with water and directed-eight tablespoonfuls every hour.

One day I received a telegram asking me to meet a train and take off a sick passenger. I went to the depot and when the train arrived, the conductor stepped off and told me that one of the passengers had been taken with a fit and the train crew would like to be relieved of the responsibility of his care. I took the patient off the train and he was able to walk, with the assistance of two men, to the hotel which was a block away. They were obliged to stop frequently as his arms and legs would jerk in a way which was alarming to his conductors and to himself. After I got him in bed, I asked whether he had been taking any medicine. At first he said no, but afterward, recollected that he had taken a dose a short time before the "fit" came on. The doctor who had given it told him to take a teaspoonful. Having no teaspoon, he drank out of the bottle that amount, as he supposed. I looked at the bottle and estimated that he had taken about five drachms. He had taken but one dose and the bottle was full when given to him. The label informed me that each teaspoonful contained, among other things, 8 minims of Squibb's fluid extract of nux vomica. On the slightest movement his muscles would jerk and twitch in a most distressing manner. He said he had what seemed an uncontrollable desire to kick and strike and jump about in every direction and it was only by the exercise of all the power of his will that he was able to refrain from doing so.

I told him that his recovery depended on his ability to lie perfectly still. I gave him a sedative and he remained quiet but wide awake for six hours when he slept, and next morning was well.

\section{REPORT OF A CASE OF COMPOSITE MON. STER-MONOMPHALIC ISCHIOPAGUS.}

Read before the Chicago Pathological Society, June 8, 1896 BY ELIZA H. ROOT, M.D.

PROFESSOR OF OBSTETRICS NORTHWESTERN UNIVERSITY WOMAN'S MEDICAL SCHOOL; ATTENDING OBSTETRICIAN TO WESLEY

M. J., Swede, blonde, age 26 ; domestic; primipara; entered the Chicago Hospital for Women and Children, March 18, 1893. Last menstrual period July 7, 1892. Patient was delivered May 4, 1893, 301 days from the beginning of last menstruation.

On entering the clinic the patient was pale and passing albuminous urine with low specific gravity, in excess of the normal quantity in the twenty-four hours. Under treatment the albumin disappeared, to again return for two weeks preceding labor. The patient complained of the weight of the tumor and of pain along the line of Poupart's ligaments.

Examination. - Inspection found the abdominal tumor very large and prominent, abdominal muscles tense and the skin greatly stretched; size of pelvis normal.

Palpation discovered two heads in fundal zone of the uterus and to right of median line. The head of the posterior fetus lay deeply in relution to the anterior uterine wall. Back of anterior fetus easily followed to breech into the iliac fossa (left). Fetal heart sounds were heard above umbilicus, a little to left of median line. Second heart sounds not heard. Although polyhydramnios was present, the uterine contents were not freely movable, except the head of the anterior fetus and at no time could the extremities be determined. Intermal examination found anterior vaginal fornix empty.

Diagnosis.-Twins; first, breech sacro-anterior; and second, breech sacro-posterior: both oblique (the vertical axis of the uterus in median line), with a provisional diagnosis of "something unusual, perhaps a double-headed baby." This last was made only half in earnest, for the idea of a composite monster had not taken serious hold upon my mind. On April 18, albumin reappeared in the urine; urine excessive in quantity, frequently amounting to 90 or more ounces in the twenty-four hours. The patient complained of feeling dull and weary. The tumor was very large and hanging well forward. The bowels were kept free with small daily doses of Epsom salts. Blaud's iron pill was given for the anemia. April 29, patient

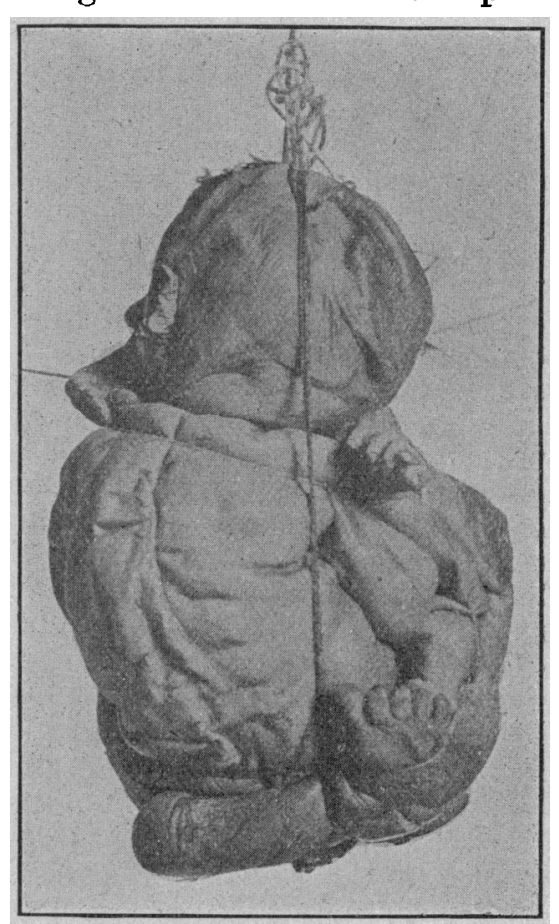

FIG. 1.-Anterior view, with foot of posterior fetus in front.

restless and does not sleep well; excessive amounts of albuminous urine continues to pass. May 3, patient began to have slight uterine contraction-pains. During the night labor was established. As there was no progress made of the presenting parts, the pains being strong, the house physician called me to the hospital on the morning of May 4. I found the os well dilated, the membranes ruptured, and a presenting mass only partly engaged in the inlet. The examin. ing finger found no feet, no namable part and slipped into a rather large orifice guarded by a border of loose folds. It was very evident my provisional diagnosis was more than true, and that I was confronted with a difficult and dangerous labor. Dr. John Bartlett kindly responded to my call for assistance. The patient was put to sleep with chloroform and the pelvis explored. which confirmed the diagnosis of double breech presenting. Pains continued strong and we proceeded to deliver. The obstetrics of the case is of considerable interest. Given a square mass present- 
ing, the feet not being found, it was fair to assume that the legs were extended, giving in each a breech presentation of the incomplete variety. The application of forceps proved useless, and further examination found the right limb of the second sacro-posterior fetus resting transversely upon the anterior ramus of the pubis (see photo. Fig. 1), the hip caught above the brim and preventing descent. All efforts to push the limb out of the way were fruitless as it had become firmly impacted between the fetus and pelvic brim.

The posterior limb of the first sacro-anterior fetus was seized and brought down giving some increase of space and a handle for traction. Descent was still unsatisfactory, and another limb, the posterior limb of the second sacro-posterior fetus was with difficulty brought down, but securing more space, partially breaking the wedge and giving an added means for traction. To and fro movements with strong traction upon the disengaged limbs brought the double breech well into the pelvic cavity.

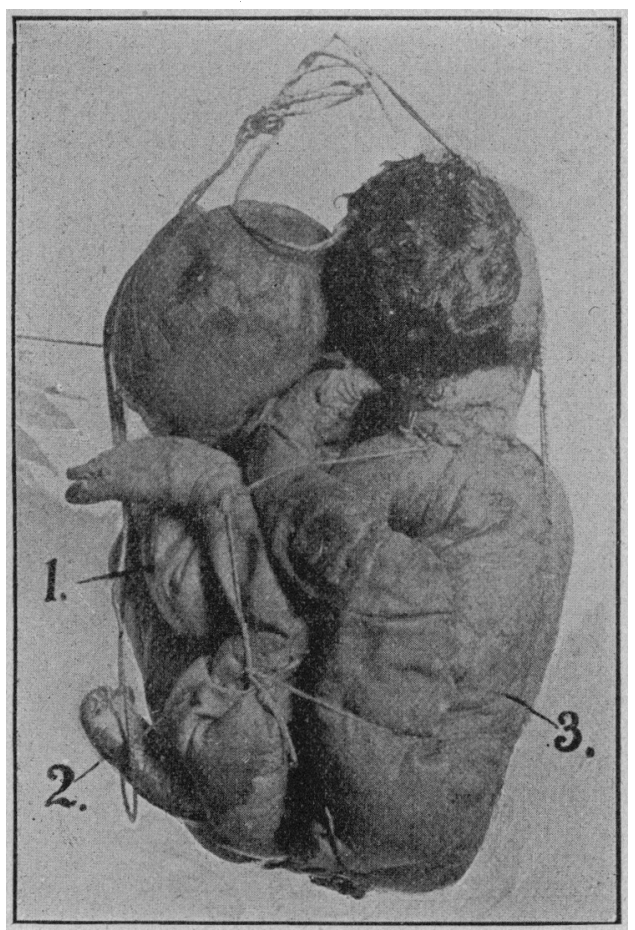

Fig. 2 -Left lateral posterior view. approximating true position in utero. 1, first sacro-anterior; 2 , foot of posterior fetus; 3 , second sacroposterior.

Advancement was now progressive though slow and difficult. The finger could now be hooked into the groin of the transversely lying limb of the second sacro-posterior fetus. This limb was now gradually pushed upward by the descent of the mass and became extended parallel to the trunk of fetus, which with the remaining anterior limb of the opposite fetus acted as a splint, making the crossing of the pelvis and advancement into the axis of the outlet extremely difficult.

At the expiration of two hours our combined efforts brought the double breech, partially rotated into the vaginal opening. The two unborn limbs were disengaged and the true nature of the deformity became evident.

As advancement of the two trunks together would further complicate labor by bringing the two heads face to face into the inlet the two bodies were separated at the pelves. The now second sacro-anterior fetus was brought down and passed the now first sacro-posterior fetus until the nape of the neck could be reached for decapitation. Delivery was soon com. pleted without hemorrhage. Traumatism of cervix and vaginal walls was considerable; the perineum was ruptured and repaired with sutures of silkworm gut. The placenta came without difficulty and weighed 31 pounds. Aseptic occlusion pad was applied to vulva and the patient put to rest greatly exhausted; pulse 150; temperature $100.6 \mathrm{~F}$.

Morning of May 5, temperature 98.6, pulse 126. Evening of same day, temperature 99.6, pulse 90. Patient could not move her lower extremities and the urine escaped without the patient's knowlege. Albumin in the urine abundant.

Recovery was uneventful though slow, the temperature rising on May 7 to 100.4 with slight headache, pulse 100. May 23, urine normal in amount for the twenty-four hours with only a trace of albumin patient anemic. June 24, the patient left the hospital in fair health. Traumatisms healed by granulations. The fetus, female, combined weight $11 \frac{1}{2}$ pounds, of nearly equal size and perfectly developed to the umbilicus. Celosomic; the liver of the second sacro-posterior fetus small and deformed, protruded into a sac formed of part of the transparent membrane enclosing and common to both abdomens.

Umbilical cord eighteen inches in length; "fat," was attached to the abdomen of the second sacroposterior fetus at or near the outer angle of the abdominal junction, which formed a sharp groove similar to that formed in a dress shield, and on the margin of the incompleted abdominal wall. At the umbilical site of first sacro-anterior fetus was an anus-like opening guarded by a few scattering stiff and short hairs resembling the rictus bristles of a bird. This proved to be the opening of the urachus, developed and serving the purpose of a urethra, there being no urethral opening in the natural or normal situation, the bladder ending in a blind pouch, the bladder receiving two ureters in a normal manner, one from a kidney of each fetus. There was oniy a vaginal orifice unsphinctered and guarded by a loose fold of tissue bearing little or no resemblance to normal structures. Vaginal canal large and received the single cervix of a two-horned uterus; ovaries and tubes normal; kidneys two in number, right kidney normal in size and location, left lobulated and situated in the hollow of the sacrum; second sacro-posterior fetus possessed three kidneys, the left situated lower than normal, while a second rested upon the promontory of the sacrum to the right of its median line, its convex outer border looking to the left as if a left kidney had slipped down from its place. The third and right kidney was undeveloped, with a helix that received blood vessels but gave off no ureter. The bladder received two ureters, one from a kidney of each fetus as in the preceding case. The meatus urinarius opened normally into a fairly developed vestibule that is guarded by two folds. Nymphæ minoræ that hooded a well developed clitoris. The labia majora are loose rudimentary folds bearing some resemblance to the normal structures. The vaginal canal is large, and receives a double cervix of a twohorned uterus, but one cervical os. Ovaries and tubes are normal. In both cases the ovaries of each uterus rested, one in the pelvic cavity of one fetus; its fellow in pelvic cavity of the opposite fetus. Both uteri were two-horned. The bladders are located in front 
of the uteri and the rectum descended between them in relation to the posterior surface of each.

to pull on. The second division of the first class, where the fission is from below, the dipygus, there being two to four legs.

Intestinal canal: Small intestines in two sets, one for each fetus. Until near the cecum they united forming a large intestine or colon; sigmoid flexure and rectum common to both.

The appearance of the external parts are peculiar. The coccyx of each protrudes, forming a process about the size of a filbert. In normal relation to each is an anal depression or pit, directly between which is located a perfect anus common to both children. To the right and left of the perfect anus are the rudimentary pudenda. The extremities, upper and lower, are well developed and the heads well shaped.

$$
\text { DISCUSSION. }
$$

Dr. Joseph B. DeLee-This is a very interesting and unu sual monster, the termination being favorable to the patient. When we consider the immense amount of dystocia monsters like this can cause, and the difficulties attending diagnosis and treatment, we can not but congratulate the Doctor. It is a peculiar fact that double monsters are said to cause much less dystocia than single ones. Professor Hohl in 1850 collated the statistics on the subject and found that 55 per cent. of single monsters caused dystocia, while only 38 per cent. of double monsters caused it. One reason is that single monsters are so likely to have displacements, such as transverse and other positions, and a large number of this class of monsters is due to hydrocephalus and enlargement of the abdomen or other cavities. Whereas double monsters will abort frequently, single monsters go to term. I remember in Berlin to have seen an abortion of three months in which there was i perfect miniature representation of the Siamese twins. The two fetuses were united together at the xyphoid appendix. In regard to the diagnosis of the double monster, there is hardly a case in which a diagnosis of it is positively made before labor. The majority of cases have gone to labor, and only when there has been obstruction has a diagnosis been made. Even then, a number of cases are difficult to diagnose, particularly where there are twins, one across another, or the two heads entering the pelvis at once or two breeches. In a single monster the diagnosis is easier. I have seen a diagnosis made of anencephalus through the abdomen by determining the breech in the fundus and no head over the inlet.

The Doctor has dealt with the division of monsters largely from a pathologic aspect. What has interested me in studying double monsters is the clinic aspect, because it is more important to the practitioner. G. Veit has written a monograph on the subject. He divides monsters into three forms. First, those where fission begins on top. The top of the monster is divided into two parts, either two heads or two faces stuck together, or the division proceeding further down, so that there are two complete heads with either one or two arms on each side. The second division is monsters united by fusion: Craniopagus, either front or back, vertex or face, ischiopagus. I think the Doctor's case was an ischiopagus in which there was dystocia of a double monster. Being united end to end, the children should have been delivered one after the other but for some reason they became doubled up like an $U$ and thus offered almost insuperable obstruction to labor. The third division comprises monsters with a point of union near the middle of the trunk. The fission is both from below upward and above downward. Example, the Siamese twins.

In the treatment of this form of dystocia the plan works nicely also. First group, fission at either end, for example, a diprosopus (two faces). Here you would do a version or craniotomy, it being simply the size of the part causing a mechanical disturbance. In general, breech presentation is more favorable in labor with monsters, because there is something down; you must get all there are and make traction on them.

The second class of monsters, where the bodies are joined end to end, seldom give trouble, as they slip through as a long cylindrical mass. This was the case of the ischiopagus monster exhibited in the museums here about six years ago.

The third division, the thoracopagi, the xiphopagi, give the most trouble. Since the band of union is often very movable it is possible to deliver one child by version and extraction and then the other likewise. Or in certain cases, bring down all four extremities, now deliver the rear child, then the other. Generally, it is a bad plan to amputate the parts which are born; true you get more room, but it disturbs the relations of the parts and you lose a good handle on which to make traction.

\section{PRIMARY SARCOMA OF THE TAIL OF THE PANCREAS.}

Read before the Chicago Pathological Society, June S, 1896. BY ERED. J. E. EHRMANN, M.D.

hate house physiciax cook covNty hospital, chicago.

Sarcoma has been found in almost all parts of the human body where mesoblastic tissue occurs. The frequency of its place of origin, however, varies greatly so that sarcomata in some locations are common, in others almost unknown. Thus primary sarcomata of the bones, eye, kidney, glands, brain, etc., occur with relative frequency, but primary sarcoma of the pancreas, for instance, is very rare. This statement is substantiated by our best known writers, some of whom emphasize their rarity; others make no reference to primary pancreatic sarcomata at all. Thus Ziegler ${ }^{1}$ writes that such growths are extraordinarily rare and Orth ${ }^{2}$ says that primary sarcoma of the pancreas is almost unheard of.

To show the relative frequency of tumors of different varieties occuring in the pancreas, I may refer to Segrè's ${ }^{3}$ table of 11,492 autopsies with 132 pancreatic tumors, of which 127 were carcinomata, 2 were cysts, 2 were sarcomata, and 1 a syphilitic growth. Segrè fails to state, however, whether the sarcomata were primary or secondary.

Some of the reports leave doubt as to the real nature of the tumor. Thus E. H. Bartley reported a case in 1880 of a patient who had vomited after meals, complained of pain in the epigastrium and emaciated rapidly. The tumor was "a spindle-celled growth, probably a carcinoma of slow growth, a scirrhus cancer, or possibly a spindle-celled sarcoma." Bruen ${ }^{5}$ in 1883 and C. Workman ${ }^{6}$ in 1892 described tumors of the pancreas, leaving doubt as to their real pathologic nature.

In 1883 Chiari $^{i}$ reported a fair-sized sarcoma of the pancreas, but considered it secondary. The patient was 43 years old, and the tumor is described as "a globular tumor in the head of the pancreas, soft, fragile, brownish-black, within a $2 \mathrm{~mm}$. thick capsule through which the tumor-mass protruded here and there. There was also a brownish tumor in the omentum, in the fossa iliaca sinistra, and in the left eye, which probably was the primary tumor." Microscop-

\footnotetext{
1 Ziegler: Lehrb. d. sp. 'ath. Anat. 1892, 619

2 Orth: Lehrb. d. sp. Path. Anat. 1887, i, 904

Segre: Schmitts Jahrb., Nov. 15, 1889

4 Bartiey: Annals Anat. and Surg. Soc. 1880, ii, 495.

ij Bos. Med. and Surg. J., 1883 , cr.

7 Virchow : Hirsch Archiv, 83, 1i, 211.
} 